\title{
Acute neurology and neurophysiology of haemolytic-uraemic syndrome
}

\author{
K J Eriksson, S G Boyd, R C Tasker
}

\begin{abstract}
Involvement of the central nervous system (CNS) is found in around $30 \%$ of children with haemolytic-uraemic syndrome (HUS). This complication is the single most common cause of mortality and also a major contributor to the morbidity associated with HUS. We reviewed 22 children with HUS and acute CNS involvement. Both global and focal derangements occurred, and in survivors, early regional EEG abnormalities-especially those in the occipital and temporal areas-were prognostically useful.

(Arch Dis Child 2001;84:434-435)
\end{abstract}

Keywords: haemolytic-uraemic syndrome; neurophysiology; outcome

Haemolytic-uraemic syndrome (HUS) is the commonest cause of acute renal failure in children in the UK. Most cases are infectious in origin (for example, Escherichia coli O157:H7, or Shigella), although sporadic, non-infectious causes (resulting from idiopathic, familial, or autoimmune diseases, drugs, or tumours) also occur. Annually, the incidence of HUS is about 1.5 per 100000 in children younger than 15 years of age. ${ }^{1}$

Neurological involvement in the acute phase of HUS occurs in $17-52 \%$ of children; the most common acute problem is generalised or partial seizure activity in more than half of those with neurological signs. ${ }^{2-5}$ Early CNS involvement is also a major contributor to chronic neurological morbidity. ${ }^{6}$ We have therefore undertaken a review of the clinical and neurophysiological features of CNS involvement during HUS in 22 children. Our purpose was to evaluate early features possibly predictive of chronic neurological sequelae.

\section{Methods and findings}

The records of 22 children treated between 1985 and 1992 at Great Ormond Street Hospital for Children, London, for clinical symptoms and laboratory findings consistent with the diagnosis of HUS were reviewed. All 22 patients had prodromal gastrointestinal symptoms, with positive stool cultures in five patients ( $E$ coli $\mathrm{O} 157: \mathrm{H} 7$ in three, rotavirus in one, and Shigella in one). There were 11 boys and 11 girls aged $0.1-13.3$ years (mean 3.3 years). All patients had experienced some neurological involvement during the acute phase of HUS and had undergone neurophysiological investigations. A total of 81 electroencephalographic (EEG) and 30 evoked potential recordings were reviewed. The type of acute neurological derangement and long term neurological outcome were also reviewed. The mean time of follow up was 4.4 years (range $0.2-7.1$ years).

\section{ACUTE NEUROLOGY AND OUTCOME}

Five of $22(23 \% ; 95 \%$ confidence interval (CI) 8 to $45 \%$ ) children died during the acute phase of HUS. The mean time from onset of symptoms was eight days (range 3-13 days). The form of acute neurological involvement seen in these patients was: acute seizures in 14 children; coma or irritability in six; and focal neurology with either hemiparesis or aphasia in the remaining two. Ten of the 22 patients had some focal ictal or motor neurology. On follow up, seven of the 18 surviving children had neurological sequelae: two cases each with complex partial seizures, cognitive deficits, or cortical visual defects; and one child with both hemiparesis and dysphasia. In 10 patients there were no long term neurological problems, although in two of these cases some deficits (homonymous hemianopia and delayed speech development) were transient for up to a year after the illness (table 1).

With regard to factors potentially predictive of outcome, seizures, alone or as part of neurological involvement, were associated with mortality or long term neurological sequelae (Kendall tau $b-0.4, p<0.05)$. For example, six of the eight children with partial or secondarily generalised seizures had neurological sequelae. When only generalised seizures were present, sequelae occurred in four of six cases. When seizures were absent, only two of eight children experienced any neurological sequelae.

EARLY NEUROPHYSIOLOGY AND NEUROLOGY

During the acute phase of HUS a variety of generalised and focal EEG features were evident in these children (table 1). In survivors, early generalised slowing in EEG activity as the sole abnormality was not associated with any long term neurological sequelae. Periodic EEG findings - intermittent activity not associated with drugs or immaturity-were associated with either death (three cases) or multiple neurological impairments (two cases). Slowing of EEG activity which was lateralised to one hemisphere was seen in four patients, one of whom developed a moderately severe cognitive deficit while another was left with hemiparesis and dysphasia. Focal discharges, emanating from the temporal region, were seen in two patients. Both subsequently developed epilepsy with complex partial seizures. Visual evoked potential studies showed reduced amplitudes in three patients, two of whom were left with visual impairments. 
Table 1 Clinical and EEG characteristics of 22 children with haemolytic-uraemic syndrome

\begin{tabular}{|c|c|c|c|c|c|}
\hline & \multicolumn{5}{|c|}{ Generalised encephalopathy } \\
\hline & $\operatorname{Sex}$ & Age & Other neurology & Early EEG & Neurological sequelae \\
\hline \multicolumn{6}{|l|}{ Coma } \\
\hline 1. & $M$ & $10 \mathrm{mth}$ & None & Slow $(1-2 / \mathrm{s})$ & None \\
\hline 2. & M & $3 \mathrm{mth}$ & None & Slow $(1-2 / s)$ & None \\
\hline 3. & $\mathrm{~F}$ & 2 y 2 mth & None & Slow $(1-2 / s)$ & None \\
\hline 4. & $\mathrm{M}$ & 2 y $8 \mathrm{mth}$ & None & Slow $(1-2 / s)$ & None \\
\hline 5. & $\mathrm{~F}$ & 13 y $3 \mathrm{mth}$ & None & Slow (right) & None \\
\hline 6. & $M$ & 2 y $9 \mathrm{mth}$ & None & Slow $(1-4 / \mathrm{s})$ & Died \\
\hline \multicolumn{6}{|l|}{ Seizures } \\
\hline 7. & $\mathrm{~F}$ & 1 y $3 \mathrm{mth}$ & None & Slow $(1-2 / \mathrm{s}$, occipital $)$ & None \\
\hline 8. & $\mathrm{~F}$ & $1 \mathrm{y} 10 \mathrm{mth}$ & None & Slow ( $2 / \mathrm{s}$, posterior) & None \\
\hline 9. & M & $1 \mathrm{y} 4 \mathrm{mth}$ & Left hemiparesis & Slow $(1-3 / \mathrm{s})$ & None (transient speech delay) \\
\hline 10. & $M$ & 3 y $2 \mathrm{mth}$ & None & Slow $(1-2 / s)$ & None (transient visual deficit) \\
\hline 11. & $M$ & 10 days & Partial seizures, coma & Periodic, multifocal discharges & Visual and developmental problems \\
\hline 12. & M & 6 y $3 \mathrm{mth}$ & Coma & Periodic, left temporal discharges & $\begin{array}{l}\text { Epilepsy (complex partial seizures); visual, } \\
\text { cognitive and motor problems }\end{array}$ \\
\hline 13. & $\mathrm{~F}$ & 1 y $8 \mathrm{mth}$ & Left hemiparesis & Periodic & Died \\
\hline 14. & $\mathrm{M}$ & 2 y $1 \mathrm{mth}$ & None & Slow $(1-3 / \mathrm{s})$ & Died \\
\hline 15. & $\mathrm{~F}$ & 3 y 6 mth & Left hemiparesis & Periodic, multifocal discharges & Died \\
\hline \multirow[t]{3}{*}{16.} & $\mathrm{~F}$ & 8 y $6 \mathrm{mth}$ & Deep coma & Periodic, multifocal discharges & Died \\
\hline & \multicolumn{5}{|c|}{ Focal derangements } \\
\hline & Sex & Age & Clinical features & Early EEG & Neurological sequelae \\
\hline \multicolumn{6}{|l|}{ Motor } \\
\hline 17. & $M$ & $3 \mathrm{mth}$ & Left hemiparesis & Slow $(2-6 / s)$ & None \\
\hline $\begin{array}{l}18 . \\
\text { Seizures }\end{array}$ & $M$ & 3 y 3 mth & Right hemiparesis, aphasia & Slow (left) & Right hemiparesis and dysphasia \\
\hline 19. & $\mathrm{~F}$ & $8 \mathrm{mth}$ & Left sided & Slow $(1-2 / s$, right $)$ & None \\
\hline 20. & $\mathrm{~F}$ & 2 y $7 \mathrm{mth}$ & Right sided & Slow $(1-4 / \mathrm{s})$ & None \\
\hline 21. & $\mathrm{~F}$ & 5 y $9 \mathrm{mth}$ & Left sided with right & Slow $(\sim 1 / \mathrm{s})$, right temporal discharges & $\begin{array}{l}\text { Epilepsy (complex partial seizures); } \\
\text { homonymous hemianopia }\end{array}$ \\
\hline 22. & $\mathrm{~F}$ & 8 y 4 mth & Left sided seizures, coma & Slow (2-3/s, right) & Cognitive deficit (moderately severe) \\
\hline
\end{tabular}

\section{Discussion}

In this review of HUS we found that during the acute phase of illness CNS involvement consisted of both generalised and focal impairments. Coma or an ictal cause of more generalised encephalopathy was confirmed by the presence of diffuse slowing of EEG activity. Focal derangements - motor, visual, or ictalsuggestive of more regional or specific cerebral processes were highlighted by focal alterations in EEG activity or by the presence of focal epileptiform discharges. In survivors, early regional EEG abnormalities, especially those in the occipital and temporal areas, were potentially useful in identifying those who would subsequently develop visual problems and epilepsy.

The pathophysiology of CNS derangement in HUS could be metabolic in origin, given the apparently diffuse nature of insults such as uraemia, hyponatraemia, or hypocalcaemia. ${ }^{7}$ Equally, focal toxin mediated mechanisms resulting in focal vascular endothelial injury or multifocal thrombotic pathology may occur. ${ }^{8}$ Clinically differentiating between these evolving general and focal processes is difficult. In this regard, five previous neurophysiological studies of HUS have described the acute findings in 36 children. ${ }^{2-5} 9$ In common with these studies we have also found in our study of 22 children that diffuse encephalopathy with irregular generalised slow delta activity is most frequently seen. However, in this review, we found a significant number of additional focal abnormalities suggesting an added focal pathophysiological process. Importantly, a unique association between repetitive discharges in the temporal region and the subsequent development of temporal lobe epilepsy was noted.
Such a focal predilection is reminiscent of the temporal lobe vulnerability seen in herpes simplex encephalitis. ${ }^{10}$

In the course of managing children with HUS, we believe that it is important to consider whether there has been any CNS involvement. Much can be established from the clinical history and examination. However, early neurophysiological investigation adds to this by confirming the presence and nature of background or focal features which may be of long term neurological importance, particularly when these are localised to the occipital or temporal regions.

This study has been financially supported by the scientific research fund of Tampere University Hospital, the Arvo and Lea Ylppö Foundation, and the Emil Aaltonen Foundation. 1 British Paediatric Surveillance Unit. Haemolytic uraemic syndrome. Royal College of Paediatrics and Child Health
BPSU 14th Annual Report 1999-2000. London: Royal ColBPSU 14th Annual Report 1999-2000. London: R
lege of Paediatrics and Child Health, 2000:21-3.

2 Bale JF, Brasher C, Siegler RL. CNS manifestations of the Bale JF, Brasher C, Siegler RL. CNS manife
HUS. Am $\mathcal{F}$ Dis Child 1980;134:869-72.

3 Sheth KJ, Swick HM, Haworth N. Neurological involvement in HUS. Ann Neurol 1986;19:90-3.

4 Cimolai N, Morrison BJ, Carter JE. Risk factors for the CNS manifestations of gastroenteritis associated HUS. Pediatrics 1992;90:616-21.

5 Dhuna A, Pascual-Leone A, Talwar D, Torres F. EEG and seizures in children with HUS. Epilepsia 1992;33:482-6.

6 Siegler RL, Pavia AT, Cook JB. Hemolytic-uremic syndrome in adolescents. Arch Pediatr Adolesc Med 1997;151: $165-9$.

7 Siegler RL. Spectrum of extrarenal involvement in postdiarrheal hemolytic-uremic syndrome. F Pediatr 1994;125: diarrheal

8 Gallo GE, Gianantonio CA. Extrarenal involvement in diarrhoea-associated hemolytic-uremic syndrome. Pediatr Nephrol 1995;9:117-19.

9 Pascual-Leone A, Dhuna AK, Janousek ST, Talwar D. EEG correlation of improvement in HUS after plasma infusion. Pediatr Neurol 1990;6:269-71.

10 Cornford ME, McCormick GF. Adult-onset temporal lobe epilepsy associated with smoldering herpes simplex 2 infection. Neurology 1997;48:425-30. 